\title{
Impact of peer education and on-site clinical services for female sex workers in Bangladesh brothels: A Link Up evaluation study
}

Population Council

Follow this and additional works at: https://knowledgecommons.popcouncil.org/departments_sbsr-hiv

Part of the Demography, Population, and Ecology Commons, Family, Life Course, and Society Commons, Gender and Sexuality Commons, International Public Health Commons, and the Maternal and Child Health Commons How does access to this work benefit you? Let us know!

\section{Recommended Citation}

Population Council. 2016. "Impact of peer education and on-site clinical services for female sex workers in Bangladesh brothels: A Link Up evaluation study," Link Up Study Brief. Washington, DC: Population Council. 


\section{IMPACT OF PEER EDUCATION AND ON-SITE CLINICAL SERVICES FOR FEMALE SEX WORKERS IN BANGLADESH BROTHELS: A LINK UP EVALUATION STUDY}

Adult HIV prevalence in Bangladesh is low ( 0.1 percent). However, in more vulnerable communities, such as female sex workers, the HIV prevalence is up to 10 times higher. ${ }^{1}$ Among women who sell sex in Dhaka City, the convergence of inequitable gender norms and deeply entrenched poverty renders these women particularly vulnerable to a host of negative social and health outcomes-including HIV and other sexually transmitted infections (STIs), sexual and gender-based violence, stigma and discrimination, and poor reproductive health. ${ }^{2-5}$

Young female sex workers (age $<25$ ) face the additional burden of navigating substantial social, emotional, and biological changes in their transition to adulthood. Despite growing global awareness of the unique vulnerabilities of adolescent girls and young women, there is a paucity of research or data and programming focusing on these younger age groups who are at greater risk of HIV due to selling or transacting sex, drug use, etc. These younger women often confront age-related discrimination and inhospitable services, which compounds their social exclusion and exacerbates their unmet health needs. ${ }^{6}$ Sex work in Bangladesh is tacitly permitted, most notably in the country's 11 registered brothels. In a conservative cultural context in which premarital sex is condemned and two-thirds of women are married by age 18 , female sex workers are particularly marginalized and stigmatized in Bangladesh.

Previous evaluations of social and health programs for female sex workers have underscored the importance of reaching women through trusted peers who can provide basic HIV and sexual and reproductive health education as well as social support. ${ }^{6}$ Furthermore, programs must overcome their social and geographic barriers to accessing health care services. In Bangladesh brothels in which women's mobility can be scrutinized and limited by the brothel madam (sordarni), one well-received HIV prevention project offered services at a nongovernmental organization (NGO) facility located within close geographic proximity to the brothels. ${ }^{4}$ However, in a qualitative assessment of this NGO clinic intervention, some female sex workers maintained that off-site services remained inaccessible,

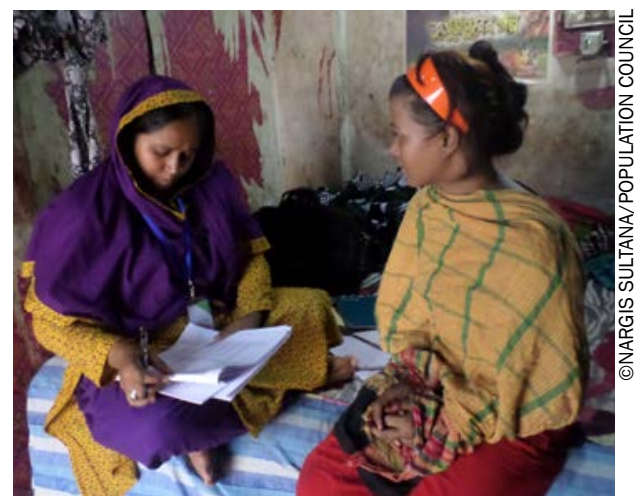

As part of Link Up, the Population Council assessed whether peer educator one-onone or group sessions and on-site satellite clinics improved SRH knowledge and behaviors among women who sell sex in three Bangladesh brothels.

\section{KEY MESSAGES}

Female sex workers who were exposed to Link Up activities were more likely to have been tested for HIV, compared to peers without such exposure.

Participants felt peer educators provided valuable social support and critical health information.

High abortion and STI prevalence suggest a need for programs to reinforce effective contraceptive use as well as condom consistency. 
even if nearby; they expressed a desire to have health care services offered within the brothel itself. ${ }^{4}$

Building on these learnings, this brief describes an evaluation of a brothel-based HIV and sexual and reproductive health and rights (SRHR) intervention that combined peer outreach with the provision of on-site clinical services in several Bangladesh brothels. The aim of this evaluation study was to assess whether peer educator one-on-one or group sessions and on-site satellite clinics improved SRHR knowledge and behaviors among women who sell sex in three Bangladesh brothels. This study was conducted by the Population Council as part of the Link Up project, a global consortium led by the International HIV/AIDS Alliance aimed at improving the SRHR of young people.

\section{STUDY METHODOLOGY}

\section{Intervention description}

From August 2014 to March 2016, Link Up partners in Bangladesh implemented a peer outreach and service delivery intervention for young female sex workers in three brothels in Dhaka and Khulna divisions: Daulatdia, Marwari Mondir, and Bagerhat. Peer educators from each brothel underwent training on communication, sexual and gender-based violence, substance use, and HIV and SRHR. Throughout the intervention period, one to two trained peer educators conducted ongoing face-to-face outreach with residents in the brothel in one-on-one and group sessions, providing basic information on HIV prevention and SRHR. In addition, an on-site Link Up clinic was opened within each brothel (referred to here as a "satellite" clinic). The clinic was open one day per week, with clinic personnel providing family planning counseling and methods (pill, injectable, and male condoms), HIV testing and counseling, STI diagnosis and treatment, antenatal and postnatal care, general pediatric and adult health consultations. When clients required services that were not available at the on-site satellite clinic-such as abortion or labor and delivery servicessatellite clinic staff would refer women to an external higher-level facility. All services were free of cost.

\section{Study design}

After approximately one year of Link Up activities, in August-September 2015, the research team conducted interviewer-administered surveys of female sex workers who resided in the three brothels in which the peer educators and satellite clinics were working. ${ }^{\text {a }}$ Eligible women were sex workers (i.e., had sex in the past 90 days and exchanged sex for money in the past 30 days), a resident of the brothel, and between the ages of 18 and 24 . All female residents who met the eligibility criteria were invited to participate in the survey, which covered demographic characteristics, SRHR, HIV-related behaviors and knowledge, and exposure to Link Up activities. The research team obtained informed consent from potential participants, after confirming that their participation was voluntary, ensuring the confidentiality of their personal information, and informing them that access to health services were not contingent on participating in the study.

We conducted qualitative interviews among a subsample of 20 women who reported that they had received services at the Link Up satellite clinic in Jessore or Daulatdia brothels. These 30- to 45-minute interviews focused on understanding the participants' experiences with and level of satisfaction with the Link Up peer educators and satellite clinic. The research team also conducted qualitative interviews with 11 Link Up peer educators and satellite clinic providers, with the aim of describing their experiences and challenges providing services to women in the brothels.

\section{Data analysis}

To compare the knowledge, attitudes, and behaviors of women who were exposed to Link Up activities and those who were not, we conducted bivariate analysis to compare outcomes of interest between women who had varying levels of exposure to Link Up activities: (1) no exposure to Link Up, (2) contact with a Link Up peer educator, or (3) both peer education contact and a visit to the on-site satellite clinic.

\footnotetext{
aThe original study design consisted of baseline and endline data collection in the intervention sites as well as in four comparison brothels, aiming to compare changes over time in the intervention brothels with changes that may have taken place in sites with no Link Up programming. However, the initiation of HIV and SRHR activities by other government and NGO programs in comparison sites during the study period undermined those sites' appropriateness for a comparative assessment of Link Up's impact. Given these circumstances, we restrict the present analysis to endline data in intervention brothels, comparing outcomes among women who did and did not have exposure to Link Up activities.
} 


\section{RESULTS}

\section{Exposure to Link Up activities}

A total of 531 female sex workers completed the endline survey in three intervention brothels. Over two-thirds (68 percent) reported participating in a oneon-one or group information session with a Link Up peer educator (referred to throughout as "peer education"), and slightly more than one-third (37 percent) received services at the satellite clinic. The women in the intervention sites received varying levels of exposure to Link Up activities (Figure 1). Everyone who attended the satellite clinic also received Link Up peer education.

\section{Participant characteristics}

The majority (64 percent) of women were aged 21-24, and this older age group was more likely to have received peer education as well as satellite services, compared to the younger age group, 18-20 (Table 1).

\section{Confidence to discuss sexual health and make good sexual behavior decisions}

The vast majority of respondents agreed they were confident to talk to a health care worker (97 percent) or their partner (92 percent) about a sexual health issue, and to make good decisions about sexual
FIGURE 1 LINK UP SERVICES RECEIVED ( $\mathbf{N}=531)$

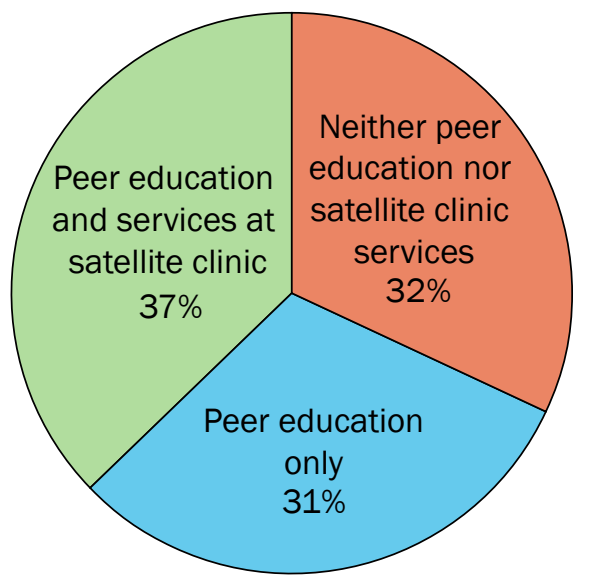

behaviors (93 percent). However, with increasing exposure to Link Up intervention activities, there were significant increases in confidence levels about sexual health decision-making. Among those who received both peer education and satellite clinic services, more than 98 percent expressed confidence to make good decisions about sexual behaviors and to talk to a partner about sexual health issues, compared to less than 85 percent who reported such confidence among women who received neither Link Up intervention (Table 2).

TABLE 1 PARTICIPANT CHARACTERISTICS, BY LEVEL OF EXPOSURE TO LINK UP ( $\mathrm{N}=531)$

\begin{tabular}{|c|c|c|c|c|c|}
\hline & $\begin{array}{l}\text { Total } \\
\text { n (\%) }\end{array}$ & $\begin{array}{l}\text { No exposure } \\
\text { to Link Up } \\
\mathrm{n}(\%)\end{array}$ & $\begin{array}{c}\text { Peer } \\
\text { education only } \\
n(\%)\end{array}$ & $\begin{array}{c}\text { Peer education and satel- } \\
\text { lite clinic services } \\
\mathrm{n}(\%)\end{array}$ & p-value \\
\hline Age & & & & & 0.033 \\
\hline $18-20$ & $191(36.0)$ & $74(43.5)$ & $58(35.4)$ & $59(29.9)$ & \\
\hline $21-24$ & $340(64.0)$ & $96(56.5)$ & $106(64.6)$ & $138(70.1)$ & \\
\hline Education & & & & & 0.16 \\
\hline None & $227(42.8)$ & $76(44.7)$ & $64(39.0)$ & $87(44.2)$ & \\
\hline Primary & $232(43.7)$ & $67(39.4)$ & $87(53.0)$ & $78(39.6)$ & \\
\hline Above primary & $72(13.6)$ & $27(15.9)$ & $13(7.9)$ & $32(16.2)$ & \\
\hline Marital status & & & & & 0.447 \\
\hline Never married & $206(38.8)$ & $73(42.9)$ & $66(40.2)$ & $67(34.0)$ & \\
\hline Married & $85(16.0)$ & $23(13.5)$ & $27(16.5)$ & $35(17.8)$ & \\
\hline Divorced/separated & $240(45.2)$ & $74(43.5)$ & $71(43.3)$ & $95(48.2)$ & \\
\hline Age first exchanged sex & & & & & 0.310 \\
\hline $9-14$ & $126(23.8)$ & $31(18.2)$ & $44(26.8)$ & $51(26.0)$ & \\
\hline $15-19$ & $305(57.6)$ & $93(54.7)$ & 97 (59.1) & $115(58.7)$ & \\
\hline $20-24$ & 99 (18.7) & 46 (27.1) & $23(14.0)$ & $30(15.3)$ & \\
\hline
\end{tabular}




\section{HIV knowledge, prevention, and risk perception}

Women who received progressively higher levels of exposure to Link Up activities had higher knowledge about HIV transmission. For example, among those who received both peer education as well as satellite clinic services, 21 percent had high HIV transmission knowledge, compared to 13 percent among those who only received peer education and 4 percent among those who had no Link Up exposure. Likewise, HIV testing was more common among those who received higher levels of exposure to Link Up activities, with 76 percent ever tested among women who received both interventions, compared to 54 percent and 44 percent among those who just received peer education or no exposure. Knowledge of testing location and confidence to get tested also were significantly higher among those who received higher levels of exposure to Link Up interventions (Table 3).

\section{I am really satisfied [with the peer}

educator] because she behaves very

well with us and loves us; she gives us advice about what to do and what not.

She tells us that we wouldn't live long

if we don't get the proper treatment so

we should try to live healthy.

-Sex worker, age 23
[The peer educators are] so much

important. As I am being able to lead

healthy life after consulting with them.

Nobody would give me good suggestion

like them. As I cannot share my prob-

lems with anyone before but now I feel

happy when I talk to them. I can share

anything with them. ...they give me sug-

gestions and they also say that if some-

one disturbs me then I can make com-

plaint against them. That's why I think

it is important for me. If it were not that

much good then so many girls wouldn't

come here. Personally I feel it is good.

-Sex worker, age 23

\section{Use of condoms and other modern contraception}

When asked about any methods they were using to prevent pregnancy, the vast majority (96 percent) reported using condoms for contraception. The pill (37 percent) and injectables (28 percent) were the next most commonly used modern family planning methods. Reported contraceptive use did not vary across levels of exposure to Link Up activities.

TABLE 2 CONFIDENCE ABOUT SEXUAL HEALTH COMMUNICATION AND DECISION-MAKING, BY LEVEL OF EXPOSURE TO LINK UP $(\mathrm{N}=531)$

\begin{tabular}{lccccc}
\hline & $\begin{array}{c}\text { Total } \\
\mathrm{n}(\%)\end{array}$ & $\begin{array}{c}\text { No exposure } \\
\text { to Link Up } \\
\mathrm{n}(\%)\end{array}$ & $\begin{array}{c}\text { Peer } \\
\text { education only } \\
\mathrm{n}(\%)\end{array}$ & $\begin{array}{c}\text { Peer education and } \\
\text { satellite clinic services } \\
\mathrm{n}(\%)\end{array}$ & p-value \\
\hline $\begin{array}{l}\text { Confident can: } \\
\quad \begin{array}{l}\text { Talk to health care worker } \\
\text { about sexual health } \\
\text { issues }\end{array}\end{array}$ & $515(97.0)$ & $157(92.4)$ & $161(98.2)$ & $197(100.0)$ & 0.090 \\
$\begin{array}{l}\text { Make good decisions } \\
\text { about sexual behaviors }\end{array}$ & $491(92.5)$ & $143(84.1)$ & $153(93.3)$ & $195(99.0)$ & 0.015 \\
$\begin{array}{l}\text { Talk with partner about } \\
\text { sexual health issues }\end{array}$ & $489(92.1)$ & $141(82.9)$ & $155(94.5)$ & $193(98.0)$ & 0.023 \\
\hline
\end{tabular}




\begin{tabular}{|c|c|c|c|c|c|}
\hline & $\begin{array}{l}\text { Total } \\
\mathrm{n}(\%)\end{array}$ & $\begin{array}{c}\text { No exposure } \\
\text { to Link Up } \\
n(\%)\end{array}$ & $\begin{array}{c}\text { Peer } \\
\text { education only } \\
\mathrm{n}(\%) \\
\end{array}$ & $\begin{array}{c}\text { Peer education and } \\
\text { satellite clinic services } \\
\mathrm{n}(\%)\end{array}$ & p-value \\
\hline $\begin{array}{l}\text { High knowledge of HIV } \\
\text { transmission }^{\dagger}\end{array}$ & $69(13.0)$ & $6(3.5)$ & $21(12.8)$ & $42(21.3)$ & 0.079 \\
\hline Ever tested for HIV & $314(59.1)$ & 75 (44.1) & $89(54.3)$ & $150(76.1)$ & 0.040 \\
\hline $\begin{array}{l}\text { Knowledge of where to } \\
\text { get HIV test (among those } \\
\text { never tested, }(n=217)\end{array}$ & $112(51.6)$ & $35(36.8)$ & $40(53.3)$ & $37(78.7)$ & 0.019 \\
\hline $\begin{array}{l}\text { High confidence about } \\
\text { HIV testing }\end{array}$ & $461(86.8)$ & $130(76.5)$ & $146(89.0)$ & $185(93.9)$ & 0.026 \\
\hline Chances of HIV infection & & & & & 0.300 \\
\hline No chance & $211(39.8)$ & $57(33.7)$ & 69 (42.1) & 85 (43.1) & \\
\hline Unlikely & $182(34.3)$ & $57(33.7)$ & $56(34.1)$ & $69(35.0)$ & \\
\hline Likely & $99(18.7)$ & $34(20.1)$ & 31 (18.9) & 34 (17.3) & \\
\hline Don't know & $38(7.2)$ & $21(12.4)$ & $8(4.9)$ & $9(4.6)$ & \\
\hline
\end{tabular}

†Summative score based on how many HIV transmission modes the participant could name, ranging from 0 to 4 of the following items: unprotected sex, sharing needles, blood transfusion, and mother-to-child transmission. Summative scores were divided into terciles (low, medium, and high knowledge).

Women reported high levels of confidence that they could use condoms during sex. However, they subsequently described very inconsistent condom use, especially with non-paying partners. A minority of participants reported that they always used condoms with paying or non-paying partners: 33 percent said they always used condoms with paying partners in the past 30 days, and 13 percent said the same with non-paying partners during that time frame (Figure 2). Reported condom use consistency did not vary across levels of exposure to Link Up activities.
Among women who received both peer education as well as satellite clinic services, a larger proportion (60 percent) reported having children compared to women who received less exposure to Link Up. Overall, 51 percent had ever had an abortion, despite very high expressed confidence to use contraception (91 percent). Just 10 percent had an unmet need for family planning, which did not significantly vary by exposure levels to the intervention (Table 4).

\section{FIGURE 2 REPORTED CONDOM USE ( $\mathrm{N}=531)$}

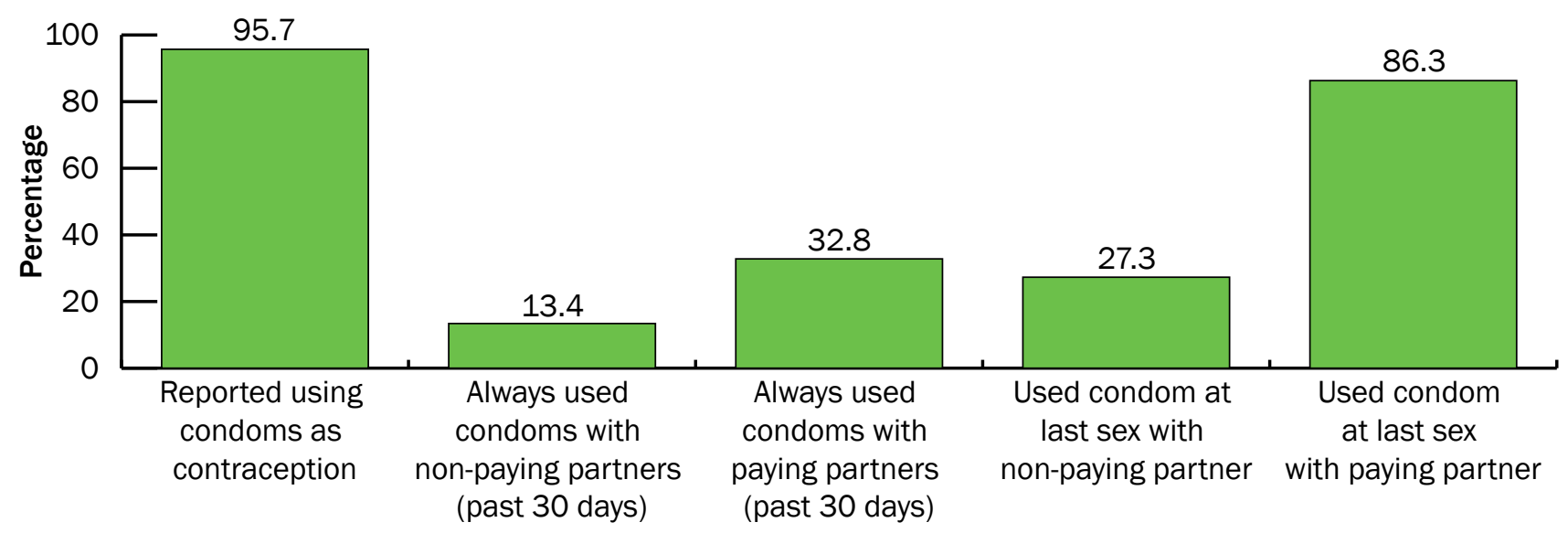




\begin{tabular}{|c|c|c|c|c|c|}
\hline & $\begin{array}{l}\text { Total } \\
\mathrm{n}(\%)\end{array}$ & $\begin{array}{l}\text { No exposure } \\
\text { to Link Up } \\
\mathrm{n}(\%)\end{array}$ & $\begin{array}{c}\text { Peer } \\
\text { education only } \\
\mathrm{n}(\%)\end{array}$ & $\begin{array}{l}\text { Peer education and } \\
\text { satellite clinic services } \\
\mathrm{n}(\%)\end{array}$ & $\mathrm{p}$-value \\
\hline Has living children $^{\dagger}$ & $180(53.4)$ & $51(51.5)$ & 49 (47.1) & $80(59.7)$ & 0.055 \\
\hline Ever had an abortion ${ }^{\dagger}$ & $172(51.0)$ & $44(44.4)$ & $57(54.8)$ & $71(53)$ & 0.129 \\
\hline $\begin{array}{l}\text { Confidence to obtain and use } \\
\text { contraceptives }\end{array}$ & $483(91.0)$ & $147(86.5)$ & $150(91.5)$ & $186(94.4)$ & 0.116 \\
\hline Unmet need for family planning ${ }^{\ddagger}$ & $53(10.0)$ & $18(10.6)$ & $18(11.0)$ & $17(8.6)$ & 0.409 \\
\hline
\end{tabular}

${ }^{\dagger}$ Among those who had been pregnant $(n=337)$.

‡Defined as women who are able to get pregnant, are not currently pregnant, and do not want a child within one year who were not using modern contraception. Modern contraception was defined as condom, injectable, implant, or intrauterine device. None were using the pill or sterilization. For women who reported condoms as their contraceptive method, they were defined as using modern contraception if they reported always using condoms in the past month with all partners (paying and non-paying), as well as using condoms at last sex with all partners.

\section{STI knowledge and symptoms}

Among women who received both peer education and satellite clinic services, a larger proportion reported high knowledge of female STI symptoms: more than one-third of those who got this most intense level of Link Up exposure had high knowledge, compared to less than 10 percent in the two lower exposure categories. Those who received both interventions also were more likely to have experienced symptoms consistent with STIs in the past six months (69 percent compared to 58 percent and 52 percent in the lower exposure categories) (Table 5).

\section{PROGRAM IMPLICATIONS AND RECOMMENDATIONS}

In the three brothels where Link Up activities took place, nearly 70 percent of young female sex workers reported having some exposure to the intervention. The one significant behavioral difference between those with and without exposure to Link Up activities was regarding HIV testing. Not only did women with more program exposure have increased testing self-efficacy, but they were more likely to have received an HIV test. They also were more likely to know where to receive a test, among those who had not yet been tested. Although overall HIV risk perception was low to moderate, the high levels of unprotected sex in this community underscore the importance of encouraging regular HIV testing for these women.

However, overall the intervention activities did not appear to have an impact on sexual behaviors. Reported contraceptive use was very high, so the lack of variation in family planning use across Link Up exposure levels is not particularly surprising. Nevertheless, the high abortion prevalence suggests that women may be using contraception inconsistently or incorrectly. Future outreach efforts and clinical services for brothel residents should emphasize the importance of using condoms with all partners.

There were strikingly high levels of recent symptoms associated with STIs, with the highest prevalence observed among women who had received exposure

TABLE 5 STI KNOWLEDGE AND SYMPTOMS, BY LEVEL OF EXPOSURE TO LINK UP ( $\mathrm{N}=531)$

\begin{tabular}{lccccc}
\hline & $\begin{array}{c}\text { Total } \\
\mathrm{n}(\%)\end{array}$ & $\begin{array}{c}\text { No exposure } \\
\text { to Link Up } \\
\mathrm{n}(\%)\end{array}$ & $\begin{array}{c}\text { Peer } \\
\text { education only } \\
\mathrm{n}(\%)\end{array}$ & $\begin{array}{c}\text { Peer education and } \\
\text { satellite clinic services } \\
\mathrm{n}(\%)\end{array}$ & $\mathrm{p}$-value \\
\hline $\begin{array}{l}\text { High knowledge of } \\
\text { female STI symptoms }\end{array}$ & $89(18.2)$ & $9(6.4)$ & $15(9.7)$ & $65(33.7)$ & 0.022 \\
$\begin{array}{l}\text { Experienced any STI symp- } \\
\text { toms in past 6 months }\end{array}$ & $311(59.9)$ & $83(51.6)$ & $93(57.8)$ & $135(68.5)$ & 0.060 \\
\hline
\end{tabular}




\section{HEALTH CARE PROVIDERS AND PEER EDUCATORS PERSPECTIVES}

Interviewed health care providers and peer educators cited unintended pregnancy and sexually transmitted infections as the most common challenges affecting women who sell sex in the study brothels. Providers and peer educators both expressed a need for more training, and providers felt the clinic space did not provide enough privacy. Providers and peer educators alike felt that their experiences as Link Up providers were rewarding, instilling in them a sense of pride in their efforts to improve women's lives in brothels.

\section{Health care providers experienced initial discomfort working in brothels}

But sometimes I feel bad when somebody thinks me as bad when they hear that I go to Daulatdia. .... Above all I feel good when I talk to them. They are also human being.

-Paramedic

...I did not feel comfortable in the very first working day in here. But from the second day I have realized that they are also human being and they need treatments. ...I am going to provide them services.

-Paramedic

\section{Health care providers expressed a need for greater privacy in satellite clinics}

And the worse thing is when patients don't want to come for full-check up here during their pregnancy.... There is no screen and privacy in the clinic for patients. It is visible from outside. So many patients do not want to lie down here. It is a big problem as it is not possible to maintain privacy here.

-Doctor

There is no separate room in the brothel and thus we have to work in the same room. There is no scope to ask everyone individually about their problems. Providing treatment and waiting is done in the same room. We have to do work in the same room. We can't maintain confidentiality.

-Counselor

\section{Health care prroviders stated there is a high prevalence of pregnancy and sexually transmitted infections}

Moreover vaginal discharge is a common female disease and 99\% females are affected by this disease. -Doctor

Nowadays most of the women want to continue with their pregnancy after getting pregnant accidentally. I try to make them realize that providing sex is not allowed during pregnancy yet they have to do it as their seniors [madams] demand that from them.

-Doctor

\section{Peer educators took pride in their work}

The best part [about being a peer educator] is that in spite of being a sex worker I am able to provide services to other sex workers. I did not understand before how to provide maternal healthcare and about various things. And after getting the training I came to know these things and I let to know the others about these. -Peer educator

I feel so proud to work as a peer educator of Link Up. Sometimes some FSW don't respond and that time I smile to them and become friendly so that they respond.

-Peer educator

\section{Health care providers and trainers expressed the need for more training and resources}

[When asked what she would do if she were in charge of supervising and training] As I have not received any training I cannot say anything about this matter. If I had received any training then I would get idea about this. But I would definitely make [Link Up providers] aware about STI, reproductive tract infections, and how does physical problem occur. I would give them proper idea on these matters.

-Doctor

According to me, we need more peer educators. Here, we are just twp peer educators and covering such a big brothel. We have to go through hardship to cover all women within this brothel and thus it is needed to include more persons as a peer educator.

-Peer educator

The more we get trainings the more we would learn. And it would be better for me for sure. It is difficult for us to keep in mind so many things as we are staying in different world. Therefore if we get the training it would be better for us. Moreover, as we are providing services thus we should provide those by making ourselves more capable and organized. So I think we need more training. 
to both Link Up activities. We are unable to determine the timing of the symptoms relative to exposure to Link Up, but it is possible that women with symptoms were more likely to take the initiative to seek counseling and clinical care. Alternatively, those women who sought out the services may have had greater pre-existing knowledge. Programs should be proactive about offering STI diagnosis and treatment.

These findings demonstrate that the combination of peer education and on-site clinical care is feasible in a Bangladesh brothel setting. Outreach and clinical staff should undergo comprehensive and ongoing HIV and SRHR training. The joint provision of social support, health education, and clinical care within the brothels may be a formidable strategy for addressing the substantial HIV and SRHR needs of young women who sell sex in Bangladesh brothels.

\section{REFERENCES}

1. UNAIDS. 2014. Country Progress Report: Bangladesh. Geneva: UNAIDS.

2. Clark, J.2015. "Bangladesh's ignored female sex workers," BMJ 350:h3470.

3. Hossain, K.K. et al. 2010. "Sexual lifestyle and socioeconomic profile of the brothel-based sex workers," Bangladesh Med J 39(3).

4. Huq, N.L.C., Chowdhury, M.E. 2012. "Assessment of the utilization of HIV interventions by sex workers in selected brothels in Bangladesh: an exploratory study," The Qualitative Report 17:1-18.

5. Nessa, K. et al. 2005. "Sexually transmitted infections among brothel-based sex workers in bangladesh: High prevalence of asymptomatic infection," Sex Transm Dis 32(1):13-9.

6. Baggaley, R. et al. 2015. "Young key populations and HIV: A special emphasis and consideration in the new WHO Consolidated Guidelines on HIV Prevention, Diagnosis, Treatment and Care for Key Populations," J Int AIDS Soc 18(2 Suppl 1):19438.

\section{LINKUP}

Link Up aims to improve the sexual and reproductive health and rights (SRHR) of one million young people affected by HIV across five countries in Africa and Asia. The project is being implemented by a consortium of partners led by the International HIV/AIDS Alliance.

For more information, visit www.link-up.org

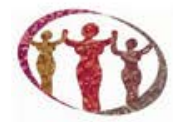

ATHENA

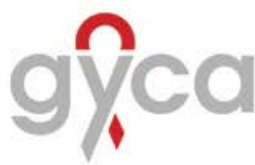

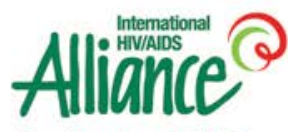

Together to end AIDS

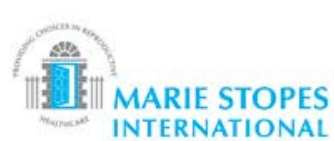

INTERNATIONAL

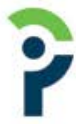

POPULATION COUNCIL

Ideas. Evidence. Impact. STOP AIDS NOW!
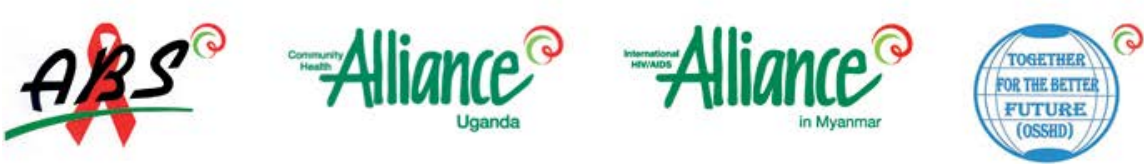

Government of the Netherlands Funded by the Ministry of Foreign Affairs of the government of the Netherlands,

POPULATION COUNCIL

Ideas. Evidence. Impact.
The Population Council confronts critical health and development issues-from stopping the spread of HIV to improving reproductive health and ensuring that young people lead full and productive lives. Through biomedical, social science and public health research in about 50 countries, the Council works with our partners to deliver solutions that lead to more effective policies, programs, and technologies to improve lives worldwide. Established in 1952 and headquartered in New York, the Council is a nongovernmental, nonprofit organization with an international board of trustees.

Suggested citation: Population Council. 2016. "Impact of peer education and on-site clinical services for female sex workers in Bangladesh brothels: A Link Up evaluation study," Link Up Study Brief. Washington, DC: Population Council.

www.popcouncil.org

(C) 2016 The Population Council, Inc. 